\title{
Comparing peer education with TBL workshop in (EBM) teaching
}

\author{
Ghobad Ramezani ${ }^{1}$, Azam Norouzi ${ }^{1}$, Eshagh Moradi ${ }^{1}$, Ghadir Pourbairamian ${ }^{1}$, Maryam Aalaa $^{1}$, Somayeh Alizadeh ${ }^{1}$, \\ Zohreh Sohrabi*1 (D)
}

\section{Abstract}

Background: Evidence-based medicine is one of the most important topics in medical sciences that requires a proper teaching method. Very few studies have evaluated EBM education outcomes through peers and TBL workshops. The purpose of this study was to compare the effect of evidence-based medicine (EBM) education through peers with TBL workshop method in medical students.

Methods: This quasi-experimental study was conducted on 42 medical students of the Faculty of Medicine in Iran University of Medical Sciences (IUMS) in 2019 who were selected through convenience sampling. Students were divided into 2 experimental and control groups based on the randomized blocking method. The data collection tools were 2 questioners that evaluated EBM knowledge and satisfaction in both intervention and control groups. The knowledge of students was compared using pretest and posttest and their satisfaction was evaluated at the end of the TBL workshop and peer education. Data were analyzed by SPSS software and descriptive tests ( $\mathrm{t}$ test and ANOVA), and significance level was set at 0.95 .

Results: A significant difference was found between the level of basic knowledge (pretest) and secondary knowledge (posttest) in the EBM education through TBL workshop method compared to peer method. The average scores gained by students in TBL workshop were 3.8 more than the peer teaching method. The results of the Satisfaction Questionnaire were $74 \%$ in control group and $86 \%$ in the experimental group.

Conclusion: EBM education through TBL workshop both increased students' knowledge and satisfaction compared to peer education. Thus, it can be concluded that providing EBM education by expert and qualified teachers through face to face teaching strategy can be effective in knowledge translation. However, peers can participate in educational sessions as facilitators.

Keywords: Evidence-based medicine, Peer education, TBL workshop, Education

Conflicts of Interest: None declared

Funding: This study was supported by Iran University of Medical Sciences and Center of Educational Research in Medical Science (CERMS), research fund (2019).

*This work has been published under CC BY-NC-SA 1.0 license.

Copyright $\odot$ Iran University of Medical Sciences

Cite this article as: Ramezani Gh, Norouzi A, Moradi E, Pourbairamian Gh, Aalaa M, Alizadeh S, Sohrabi Z. Comparing peer education with TBL workshop in (EBM) teaching. Med J Islam Repub Iran. 2020 (29 Jun);34:70. https://doi.org/10.47176/mjiri.34.70

\section{Introduction}

One of the recent global trends in medical education is

Corresponding author: Dr Zohreh Sohrabi, sohrabiz@iums.ac.ir

1. Center of Educational Research in Medical Science (CERMS), Department of Medica Education, School of Medicine, Iran University of Medical Science, Tehran, Iran questioning and finding evidence for decision-making. Ev-

\section{$\uparrow$ What is "already known" in this topic:}

Evidence-based medicine is the confident, accurate, and thoughtful use of the available best evidence to make decisions in caring for patients. Choosing an appropriate teaching method to teach EBM to students is important. The purpose of this study was to compare the effect of evidence-based medicine (EBM) education through peers with TBL workshop method in medical students.

\section{$\rightarrow$ What this article adds:}

The results of this study showed that Evidence-Based Medicine education through peers and TBL workshop has a positive effec $t$ on the knowledge levels of the students, but education through TBL workshop method was far more effective than the peer me thod. 
idence-based medicine (EBM) education means the integrates professional knowledge with the best available empirical evidence for decision-making $(1,2)$. EBM emphasizes the combination of research and documentation with clinical practices. The key assumption of EBM is involvement of clinical staff in delivering patient care. Therefore, EBM should be used to maximize effectiveness (3). The role of the clinical staff is very important in EBM education and its institutionalization. Also, choosing an appropriate method to teach EBM to students is highly important. In recent years, higher level medicine students (peers) have extensively been training undergraduates at Iran University of Medical Sciences (IUMS).

Teaching and learning through peers is a form of education in which those with the same social network help each other in learning and learn themselves in the process (4). However, this method is not used as much in formal education .This is a useful method to prepare students for their future role as medical instructors (5). The results of Buckley et al's study showed that education through peers helps students to overcome formal lecture phobia (6). Also, the results of the study by Mehrabee et al suggested that learning through the help of peers improved clinical reasoning skills in dental students in an internship course (4). However, peer education has some limitations, such as reducing teacher-student contact time and lack of formal evaluation (7).

Holding workshops is another EBM education method. In fact, the reliability and comfortability of workshops was confirmed in the study by Sastre et al. They found positive effects of EBM short workshop on students' attitudes toward EBM, personal confidence in using EBM, students' use of EBM concepts in clinical notes, and students' use of EBM-based websites (8).

In this study, holding a workshop with TBL training strategy was used to teach EBM. TBL as an instructor-directed and learner-centered strategy is an appropriate method for medical education. In this strategy, students are responsible for active participation in class and they are expected to apply their knowledge in the form of problem-solving (9).

TBL is a type of collaborative learning that aims to increase the learners' skill to attain higher levels of learning by working in a team and being an active learner. TBL allows the teacher to manage multiple small groups in a single class at the same time (9). TBL consists of 3 steps that are repeated: preparation, application, and evaluation. At the preparation stage, students must study the content before the class session; then, a quiz is taken at the beginning of the next session. At the application stage, students, who have been placed in a small group as a team, discuss the real problems of the world and give feedback to faculty members. The final stage is the assessment of student learning (10).

The purpose of this study was to compare the effect of evidence-based medicine (EBM) education through peers with TBL workshop method in medical students.

It is hoped that the results will motivate professors and students to apply the best learning approach.

\section{Methods}

\section{Study design}

This was a quasi-experimental study in which 42 medical students of the Faculty of Medicine in Iran University of Medical Sciences were selected through convenience sampling.

\section{Materials and Participants}

The participants were placed into 2 intervention (TBL workshop) and control (peer) groups, based on the randomized blocking method.

Workshops as an educational intervention were held with team-based learning methods for 2 days. Workshop sessions began with an introductory explanation of the concept of evidence-based medicine. Group work was used to work on EBM topics, such as search and critical appraisal. Students were asked to study the topics which had previously been given to them before the session and were required to attend the meeting prepared. Then, to ensure individual readiness in each session, a questionnaire containing 24 multiple-choice questions related to the topic of the same session was given to the students, and the students were asked to answer the questions in a timely manner. Then, participants were placed into groups of 10 to 12 , and the groups started the discussions and responded to the same questions at the deadline. Also, at this stage, each group were given an opportunity to express the group's responses, and then the groups started the discussions. Teachers also assisted students in consolidating their education at this stage.

In the peer education group (control group), a student holding a master's degree who had previously completed this course played the role of the instructor. Training was provided as a lecture and practical individual work. The EBM class through peer education was held for 4 days.

Two questionnaires were used to collect data. The first questionnaire was designed by EBM teachers in 2 sections. The first section was demographic information and the second included 24 questions related to the topics presented in the EBM education through TBL workshops and peer education. Using this questionnaire, data were collected using pretest and posttest; also, face validity of this questionnaire was confirmed by 3 medical teachers, and content validity of the questionnaire was obtained by some faculty members and experts (criteria for selecting the participants for confirming validity was having the knowledge and expertise required for evaluation and EBM). The Waltz and Basel method was used to evaluate the content validity index (11). The number of experts was 8 and the CVR index was 0.90. To calculate CVI, experts determined relevance, simplicity, and clarity of each item. The score obtained for CVI was equal to 0.86 . Reliability was obtained using the testretest method in 10 medical students (Cronbach's alpha = 0.82). The second questionnaire was Satisfaction Questionnaire, which has been approved before (This questionnaire is routinely provided by universities to assess satisfaction after completion of training courses.). The Satisfaction Questionnaire was used at the end of EBM education in both groups and includes 12 questions about quality of the 
presentation of the topics, quality of the questions and answers, relevance of the content of the speech to the goals, amount of provided new information, applicability of the provided content, developing a new attitude in the field of management and planning, interaction of work in groups, improvement of information after group work, and the faculty's readiness for presentation and assessment of the program. Data were collected using pretest-posttest.

Data were collected using pretest posttest by a questionnaire, and Satisfaction Questionnaire was completed by students. The data were analyzed using descriptive and analytical tests (t test and ANOVA, with 95\% confidence interval) by SPSS software (12).

\section{Results}

Based on the results of Table 1, the mean of the experimental group was 55.28 at pretest and 112.36 at posttest, and that of the control group was 53.56 at pretest and 94.28 at posttest.

According to Table 2, there was no significant difference between the 2 groups in pretest.

As demonstrated in Table 3, basic knowledge level score in EBM education through peers was 2.52 in pretest, which was changed to 3.84 in the posttest, and this change was statistically significant ( $\mathrm{p}=0.001)$.

Students' level of knowledge in EBM education through TBL was 3.39 in the pretest, which increased to 7.41 in the posttest, and this increase was statistically significant $(\mathrm{p}=0.001)$ (Table 4).

According to Tables 3 and 4, there were significant differences between the 2 groups in knowledge level at posttest. Evidence-based education by TBL workshop had a significant positive effect on students' learning compared to peer teaching method.

\section{Discussion}

Using a variety of learning styles is one of the keys to the success of effective teaching in universities (13). This study demonstrated that EBM (Evidence-based medicine) education through peers and TBL workshop had a positive effect on the knowledge levels of students, but education through TBL workshop method was far more effective than peer method. It can be concluded that due to the skills of the professors who organized the workshop and their level of expertise and experience, they were able to induce more educational effects on the learners. The students were pleased to participate in the course, and in their view, familiarity with EBM was essential for a proper clinical performance. Accordingly, it can be expected that further long-term and supplementary TBL workshops be welcomed by students. In a similar study in Tabriz university of Medical Sciences, 1 week of summer school about EBM, including teambased learning (TBL), seminar-style presentation, and EBM journal club, were held; pre questionnaire and post questionnaire and reflective journals suggested that this course was efficient and medical students found it useful and satisfying (14). In a study in which the same learning strategy was used and TBL was used to teach EBM to firstyear residents, results showed that TBL was an effective way to teach EBM to residents with different disciplines (15). EBM has been accepted as a new and reliable model in medical science, and EBM education is also aimed at using the serious, explicit, and rational of the best common evidence for decision-making (16). EBM education can lead to deep learning by enhancing problem-solving skills, and active participation of learners in the process of learning, confronting real situations, and using comprehensive sources (17). Learning has 3 levels: strategic, superficial, and deep (18). EBM education has also been used to develop decision-making skills in medical students. In the recent years, the importance of learning through peers in medical education has been growing. Teaching and learning from peers is an effective educational intervention for health science students in clinical settings. Due to the high volume of medical and clinical work, efforts should be made to identify and train peers as the next generation of

Table 1. Comparison of the mean and standard deviation of pretest and posttest of the 2 groups in the variable of basic knowledge level

\begin{tabular}{|c|c|c|c|c|c|c|}
\hline Group & \multicolumn{4}{|c|}{ Pretest } & \multicolumn{2}{|l|}{ Posttest } \\
\hline & \multicolumn{3}{|c|}{ Standard Deviation } & Mean & Standard Deviation & \multirow{3}{*}{$\begin{array}{c}\text { Mean } \\
112.36 \\
94.28\end{array}$} \\
\hline Experimental & \multirow{2}{*}{\multicolumn{3}{|c|}{$\begin{array}{l}0.67 \\
0.71 \\
\end{array}$}} & 55.28 & 0.47 & \\
\hline Control & & & & 53.56 & 0.56 & \\
\hline & Group & Numerous & Average & Standard Deviation & Standard Error of Mean & P value \\
\hline Basic Knowledge & Experimental & 22 & 3.3241 & 0.4516 & 0.3285 & 0.142 \\
\hline Level & Control & 20 & 3.3184 & 0.5007 & 0.6814 & \\
\hline
\end{tabular}

Table 3. Paired t test was used to examine the difference in basic knowledge and secondary knowledge of students in EBM education through peers in pretest and posttest

\begin{tabular}{lcccc}
\hline Variable & Stage & Mean & Standard Deviation & $\mathrm{t}$ \\
\hline Knowledge & Pretest & 2.25 & 4.18 & 3.76 \\
& Posttest & 3.84 & 4.22 & 0.001 \\
\hline
\end{tabular}

Table 4. Paired t test was used to examine the difference in basic knowledge and secondary knowledge of students in EBM education through TBL workshop in pretest and posttest

\begin{tabular}{lcccc}
\hline Variable & Stage & Mean & Standard Deviation & $\mathrm{t}$ \\
\hline Knowledge & Pretest & 3.39 & 2.54 & P value \\
& Posttest & 7.41 & 2.93 & 0.001 \\
\hline
\end{tabular}


clinical educators. Senior peers have more clinical experiences than college students who study for 1 year or more. Students benefit as teachers and learners at the same time. Peer-to-peer learning increases student active engagement and increases student responsibility in learning. In this study, students were more satisfied with the workshop method; thus, peer education may be effective as a complementary method and peers can act as teacher assistants in the classroom.

Ahmadi et al, in their study titled, "Effectiveness of teaching evidence-based medicine to undergraduate medical students: a BEME systematic review", concluded that EBM teaching strategies can potentially improve knowledge, attitudes, and skills in undergraduate medical students (17).

Kimyai et al (2011) examined the effect of peer education on the practical skills of dentistry students and concluded that this method should be considered as a complementary educational method rather than an independent method (19). The result of the study of Taheri et al about the effect of an EBM workshop on undergraduate medical students' skills in applying EBM showed that EBM workshop improved clinical question development and searching strategies (20). Also, considering the positive effect of EBM education on students' knowledge and awareness, educating learners about the concepts of EBM is highly recommended both theoretically and practically.

In this study, TBL strategy was used in the workshop and the success of the workshop method might have been due to the use of TBL training strategy. In fact, the results of a longitudinal study of medical students who have experienced TBL sessions suggested that TBL improves medical students' team work, self-learning, problem-solving, communication skills, and professionalism (21). Tai et al showed that TBL promoted a high level of students' engagement and interaction in class (10). Thus, it is recommended that the effectiveness of TBL workshop be examined in future studies.

\section{Conclusion}

TBL workshop can be a precursor to increase professional knowledge and skills. Considering the importance of EBM education in providing the highest quality and effective care, it is suggested that educational workshops and appropriate training be conducted on a regular basis and for medical students.

\section{Limitations}

Considering the type of study (quasi-experimental), we had some limitations, including small sample size and lack of generalizability of the results. Furthermore, in this study, EBM skills were assessed immediately after the workshop, and thus its long-term results were not examined.

\section{Ethical statement}

The code of ethics was obtained from the Medical Education Research Center of Iran University of Medical Sciences. Also, permission was obtained from the Ethics Committee of Faculty of Medicine at Iran University of Medical Sciences. Moreover, necessary explanations and research objectives were explained to the participants (Moral code number: 1247).

\section{Acknowledgments}

The authors of this study are grateful for the cooperation of all the participants in the study.

\section{Conflict of Interests}

The authors declare that they have no competing interests.

\section{References}

1. Eddy DM. Evidence-based medicine: a unified approach. Health aff. 2005;24(1):9-17.

2. Kim JS, Gu MO, Chang H. Effects of an evidence-based practice education program using multifaceted interventions: a quasiexperimental study with undergraduate nursing students. BMC Med Educ. 2019;19(1):71.

3. Haas SA. Resourcing evidence-based practice in ambulatory care nursing. Nurs Econom. 2008;26(5):319.

4. Mehrabi S, Sanaee Moghadam Z, Rabbani M, Nikenam H, Roozbehi A. The effect of peer assisted learning on clinical reasoning in students of medicine in clerkship and internship phases in Urology Ward of Yasuj Shahid Beheshti Hospital. Armaghanej. 2011;16(5):480-8.

5. Hajihosseini F, Izadi A, Mahboobi M, Mohammadtabar R. Effect of Peer Education on Practical Skills Learning of Nursing Students in Clinical Skill Lab (CSL) of Mazandaran University of Medical Sciences. Biann J Med Edu Develop Center. 2013;1(1):13-7.

6. Buckley S, Zamora J. Effects of participation in a cross year peer tutoring programme in clinical examination skills on volunteer tutors' skills and attitudes towards teachers and teaching. BMC Med Educ. 2007;7(1):20.

7. Goldsmith M, Stewart L, Ferguson L. Peer learning partnership: An innovative strategy to enhance skill acquisition in nursing students. Nuedu today. 2006;26(2):123-30.

8. Sastre EA, Denny JC, Mccoy JA, McCoy AB, Spickard A 3rd. Teaching evidence-based medicine: Impact on students' literature use and inpatient clinical documentation. Med Teach. 2011;33(6):e306-e12.

9. Parmelee D, Michaelsen LK, Cook S, Hudes PD. Team-based learning: a practical guide: AMEE guide no. 65. Med Teach. 2012;34(5):e275e87.

10. Tai BC, Koh WP. Does team learning motivate students' engagement in an evidence-based medicine course? Ann Acad Med Singapore. 2008;37(12):1019.

11. Waltz CF, Bausell BR. Nursing research: design statistics and computer analysis: Davis FA; 1981.

12. Floyd KS, Harrington SJ, Santiago J. The effect of engagement and perceived course value on deep and surface learning strategies. Informing Sci J. 2009;12(10):181-90.

13. Salimi J, Ramezani G. Identification of the Components of Effective Teaching and Assessment of Teaching Case Study: University of Applied Science of Kurdistan Province). Quart J Edu Measur Evaluat Stud. 2015;4(8):33-61.

14. Fereshteh F, Hadi M, Negar TT, Sakineh H, Neda M, Mohammadali $\mathrm{H}$, et al. Evidence based medicine summer school for undergraduate medical students using innovative methods. Med Sci. 2018;22(92):37784.

15. Mousavi MA, Amini M, Delavari S, Seifi A. Using Team-Based Learning to Teach Evidence-Based Medicine to First-Year Residents. Acta Fac Medicae Naissensis. 2019;36(1):60-8.

16. Kim YS, Kim J, Park MM. Factors influencing competency in evidence-based practice among clinical nurses. J Korean Acad Nurs Administ. 2015;21(2):143-53.

17. Parchebafieh S, Safavi M, Mashouf S, Salehi S, Zanjani SE, Bakhshandeh H. Effect of using Peer Assisted Learning Approach on clinical Self-efficacy of Nursing Students at Islamic Azad University of Tehran Medical Sciences Branch. J Nurs Edu. 2018;vol 6(6):8-15.

18. Ahmadi SF, Baradaran HR, Ahmadi E. Effectiveness of teaching evidence-based medicine to undergraduate medical students: a BEME systematic review. Med teacher. 2015;37(1):21-30.

19. Kimyai S, Jafari Navimipour E, Mohammadi N. The effect of peer education on practical skills training of dentistry students in restorative 
preclinic. Iran J Med Edu. 2011;11(4):418-24

20. Taheri H, Mirmohammad Sadeghi M, Adibi I, Ashourioun V, Sadeghizadeh A, Adibi P. The effect of an evidence based medicine workshop on undergraduate medical students' skills in applying EBM. Iran J Med Edu. 2006;6(2):71-8

21. Zgheib NK, Dimassi Z, Bou Akl I, Badr KF, Sabra R. The long-term impact of team-based learning on medical students' team performance scores and on their peer evaluation scores. Med Teach. 2016;38(10):1017-24 